\title{
1995: 40 AÑOS UPN
}

Durante los primeros 40 años de existencia, la Universidad Pedagógica Nacional ha tenido, en el contexto de la educación del país, la oportunidad de formar a miles de ciudadanos colombianos, desde los niveles de la educación primaria hasta los profesionales en las diferentes modalidades de licenciaturas y en los programas de postgrado que actualmente ofrece.

En esta perspectiva se puede afirmar que la Universidad Pedagógica Nacional ha contribuido al desarrollo educativo y cultural del país, formando profesionales idóneos, altamente comprometidos con el mejoramiento integral de las condiciones de vida de los colombianos; ha realizado investigaciones sobre problemas educativos y culturales en los diferentes escenarios de la comunidad colombiana; ha proyectado sus logros a otros sectores de la comunidad educativa con el ofrecimiento de diferentes tipos de eventos, programas y publicaciones; $y$ ha divulgado las tendencias e innovaciones del quehacer educativo y cultural para beneficio de la sociedad en general y de la comunidad educativa colombiana en particular.

La preservación del acervo cultural, el diseño y elaboración de estrategias para la trasmisión y diseminación de los contenidos de los diferentes discursos elaborados por el hombre y la producción de una cultura y un ambiente pluralista, fueron las caracteristicas que acompañaron a las universidades que surgieron en su época.

La idea de relevancia social, de compromiso con el desarrollo de la sociedad, solamente surge a mediados de nuestro siglo, con el concepto de extensión como dimensión esencial de la enseñanza y de la investigación. Esta circunstancia le proporcionó legitimidad y prestigio, cumpliendo así con las funciones y la misión de la universidad al encontrar preocupaciones que van más allá de las tradicionales de formación de profesionales de la educación a las de producir conocimientos en las disciplinas y en la enseñanza-aprendizaje de las mismas, y últimamente, en la creación de investigadores.

Estas funciones son las que, a pesar de las dificultades presentadas, ha venido realizando la Universidad Pedagógica Nacional, las cuales posibilitan su presencia y legitiman su importancia para el desarrollo educativo del país y por ende abre las puertas al desarrollo económico, político y social desde una perspectiva de formación de las futuras generaciones de colombianos en los valores y principios éticos y civilistas, como fundamento de una nueva sociedad democrática, necesaria para la consolidación de la paz a la luz del siglo XXI. 